\title{
Avaliação de um cianoacrilato quanto à esterilidade e atividade biocida
}

\author{
Evaluation of sterility and biocide activity on microorganisms of commercially \\ availablecyanoacrylate
}

\author{
Emerson Lioji Ueda ${ }^{1}$ \\ Ana Luísa Hofling-Lima ${ }^{2}$ \\ Luciene Barbosa de Sousa ${ }^{3}$ \\ Maira Sacata Tong $\mathbf{u}^{4}$ \\ Maria Cecilia Zorat $\mathbf{Y u}^{5}$ \\ Acácio Alves de Souza Lima ${ }^{6}$
}

Universidade Federal de São Paulo - UNIFESP, Departamento de Oftalmologia, Laboratório de Oftalmologia. Rua Botucatu, no 820 - São Paulo (SP) CEP 04023-062

${ }^{1}$ Ex-estágiário do setor de Trauma Ocular e Pronto Socorro da Universidade Federal de São Paulo - UNIFESP.

${ }^{2}$ Chefe do Laboratório de Oftalmologia da Universidade Federal de São Paulo - UNIFESP.

${ }^{3}$ Chefe do Setor de Doenças Externas e Córnea da Universidade Federal de São Paulo - UNIFESP.

${ }^{4}$ Doutora em Oftalmologia pela Universidade Federal de São Paulo - UNIFESP.

${ }^{5}$ Biomédica responsável da Universidade Federal de São Paulo - LOFT-UNIFESP.

${ }^{6}$ Pós-graduando da Universidade Federal de São Paulo - UNIFESP.

Endereço para correspondência: Instituto de Olhos de Marília - Avenida Rio Branco, 285 - Marília (SP) CEP 17500-000

E-mail: elueda@uol.com.br

Recebido para publicação em 19.03.2003

Versão revisada recebida em 31.07.2003

Aprovação em 30.01.2004

Nota Editorial: Pela análise deste trabalho e por sua anuência na divulgação desta nota, agradecemos ao Dr. Haroldo Vieira de Moraes Jr.

\begin{tabular}{|c|}
\hline RESUMO \\
\hline $\begin{array}{l}\text { Objetivo: Avaliar a esterilidade do cianoacrilato Super Bonder }{ }^{\circledR} \text { e sua } \\
\text { atividade biocida sobre microrganismos. Métodos: Para verificação de } \\
\text { contaminação, vinte amostras de cianoacrilato Super Bonder }{ }^{\circledR} \text { foram } \\
\text { aplicadas em meio "brain heart infusion" (BHI) e incubadas a } 37^{\circ} \text { C. Após } \\
7 \text { dias de incubação, foram retiradas e semeadas em placas de ágar sangue, } \\
\text { chocolate e Sabouraud. Para determinação do efeito biocida, as cepas } \\
\text { Staphylococcus xylosis, Staphylococcus aureus e Pseudomonas aerugi- } \\
\text { nosa da American TypeCulture Collection (ATCC) foram utilizadas em três } \\
\text { diferentes modelos, alterando a maneira de aplicação do adesivo cianoa- } \\
\text { crilato Super Bonder (em microescavações, em tubos e sobre o ágar). } \\
\text { Resultados: Não foi observado crescimento positivo nas amostras de } \\
\text { cianoacrilato semeadas em "brain heart infusion". Nas placas com micro- } \\
\text { escavações observou-se crescimento de } P \text {. aeruginosa e inibição de } \\
\text { S. aureus e } S \text {. xylosis. Após a retirada do adesivo, houve crescimento } \\
\text { bacteriano em todas as microescavações. Nas placas semeadas com } \\
\text { S. aureus e } S \text {. xylosis houve formação aparente de halos de inibição, o que } \\
\text { não ocorreu com } P \text {. aeruginosa. Como resultado não é verdade que não } \\
\text { foi demonstrado atividade biocida do cianoacrilato em relação às bactérias } \\
\text { S. aureus, } S \text {. xylosis e } P \text {. aeroginosa. Conclusão: Os testes de esterilidade } \\
\text { realizados demonstraram que o cianoacrilato Super Bonder }{ }^{\circledR} \text { é alternativa } \\
\text { segura quanto à esterilidade. Não foi demonstrado nenhum efeito bacte- } \\
\text { riostático ou bactericida em relação a } S \text {. aureus, } S \text {. xylosis e } P \text {. aeruginosa, } \\
\text { o que indica a necessidade da manutenção da antibioticoterapia. }\end{array}$ \\
\hline
\end{tabular}

Descritores: Cianoacrilatos/uso terapêutico; Adesivos teciduais; Córnea/lesões; Antiinfecciosos; Pseudomonas aeruginosa/isolamento \& purificação; Staphylococcus/isolamento \& purificação

\section{INTRODUÇÃO}

O uso de adesivos teciduais para tratamento de afecções corneais com afinamento e micro-perfurações já é bastante divulgado e aceito ${ }^{(1-5)}$. O adesivo tecidual de cianoacrilato mais empregado em Oftalmologia é o Hystoacril Blue $^{\circledR}$, o qual é comercializado estéril e com baixa toxicidade corneal ${ }^{(6)}$.

A dificuldade em obtenção e o alto custo do Hystoacril Blue ${ }^{\circledR}$ em nosso meio torna importante a busca por outros produtos. O cianoacrilato Super Bonder $^{\circledR}\left(2\right.$-metil cianoacrilato ${ }^{(5-6)}$, comercializado para finalidades não médicas, é utilizado com eficácia comprovada para pequenas perfurações de córnea.

Os estudos descrevem, em determinados tipos de cianoacrilato, um 
possível efeito bactericida sobre Streptococcus ${ }^{(7)}$ e outros microrganismos como Escherichia coli e Staphylococcus aureus $^{(8)}$.

Como o cianoacrilato Super Bonder ${ }^{\circledR}$, na forma como é comercializado, não apresenta em sua embalagem indicações de esterilidade, idealizamos este estudo para avaliar possíveis contaminações bacterianas ou fúngicas deste produto e avaliar sua atividade biocida em relação a bactérias.

\section{MÉTODOS}

\section{Teste de esterilidade em amostras de cianoacrilato Super Bonder ${ }^{\circledR}$}

Amostras de 20 bisnagas de cianoacrilato Super Bonder ${ }^{\circledR}$, colhidas de diferentes estabelecimentos comerciais, foram testadas, inoculando-se 10 gotas de cada bisnaga em $4 \mathrm{ml} \mathrm{de}$ meio de cultivo líquido BHI (Brain Heart Infusion).

Após a inoculação, os meios foram incubados a $37^{\circ} \mathrm{C}$ durante 7 dias, quando se utilizou alça de platina para retirada de amostras de cada tubo, as quais foram semeadas em placas de ágar sangue, chocolate e Sabouraud.

As placas foram examinadas diariamente para verificação de crescimento microbiano, sendo que as de ágar sangue e chocolate eram mantidas a $37^{\circ} \mathrm{C}$ por sete dias, e as de Sabouraud em temperatura ambiente por 15 dias.

\section{Avaliação da ação inibitória do cianoacrilato Super Bonder $^{\circledast}$ sobre o crescimento bacteriano}

Para testar a hipótese de que o adesivo formado na polimerização do cianoacrilato poderia ter ação bactericida ou bacteriostática, idealizou-se três experimentos "in vitro", utilizandose três cepas bacterianas: Staphylococcus xylosis (ATCC29771), Staphylococcus aureus (ATCC25923), Pseudomonas aeruginosa (ATCC15442). Os controles de cada experimento foram feitos sem a utilização do adesivo cianoacrilato.

\section{Experimento 1:}

Nos meios de ágar sangue foram realizadas microescavações com a introdução da ponta aquecida de uma agulha de platina, de $1 \mathrm{~mm}$ de diâmetro, onde semeou-se $0,1 \mathrm{ml}$ de uma suspensão contendo $1,5 \times 10^{8} \mathrm{CFU} / \mathrm{ml}$ de cada cepa estudada.

As placas permaneceram em temperatura ambiente por 30 minutos para secagem do inóculo e então, uma gota do adesivo foi utilizada para recobrir as microescavações. Em contato com o ágar, ocorreu uma polimerização imediata do adesivo. As placas foram incubadas em estufa a $37^{\circ} \mathrm{C}$ e o crescimento bacteriano foi avaliado após 24, 48 e 72 horas de incubação.

Após este período, a película formada pelo adesivo foi removida, inoculada em meio líquido BHI e incubada em estufa a $37^{\circ} \mathrm{C}$, para avaliação de crescimento bacteriano após 24 horas. As placas de ágar sangue foram mantidas em incubação a $37^{\circ} \mathrm{C}$, durante 24,48 e 72 horas.

\section{Experimento 2:}

Cada cepa de bactéria estudada, em suspensão contendo $1,5 \times 10^{8} \mathrm{CFU} / \mathrm{ml}$, foi semeada em placas de ágar sangue pela técnica de esgotamento. Sobre a área semeada foram instiladas gotas de cianoacrilato Super Bonder ${ }^{\circledR}$ de modo a formar um disco com $6 \mathrm{~mm}$ de diâmetro. A presença de crescimento bacteriano foi avaliada após 24,48 e 72 horas de incubação a $37^{\circ} \mathrm{C}$.

\section{Experimento 3:}

Em tubos de ensaio contendo meio sólido de MüellerHinton foram feitas perfurações com agulha de platina, com 20 $\mathrm{mm}$ de extensão, onde se semeou $0,1 \mathrm{ml}$ das suspensões contendo $1,5 \times 10^{8} \mathrm{CFU} / \mathrm{ml}$ de cada espécie bacteriana e aplicou-se o cianoacrilato. A presença de crescimento bacteriano foi avaliada após 24,48 e 72 horas de incubação a $37^{\circ} \mathrm{C}$.

\section{RESULTADOS}

\section{Teste de esterilidade em amostras de cianoacrilato Super Bonder ${ }^{\circledast}$}

Não houve crescimento bacteriano em nenhum dos tubos contendo BHI e cianoacrilato até o sétimo dia de incubação. As amostras retiradas desses tubos e semeadas em placas de ágar sangue, chocolate e Sabouraud também não apresentaram crescimento de microrganismos.

\section{Avaliação da ação inibitória do cianoacrilato Super Bonder $^{\circledast}$ sobre o crescimento bacteriano}

\section{Experimento 1:}

Houve crescimento das cepas testadas no trajeto das microescavações nas placas controle (sem o adesivo). Nas placas de teste, no local onde a película do adesivo estava recobrindo a micro-escavação houve crescimento de Pseudomonas aeruginosa e inibição do crescimento de $S$. aureus e S. xylosis.

Após a retirada da película, observou-se a presença de crescimento de $S$. aureus e $S$. xylosis na área escavada.

Observou-se crescimento bacteriano em todos os tubos com meio BHI que receberam as películas de adesivo que recobriam as micro-perfurações.

\section{Experimento 2:}

Nas placas semeadas com as amostras de Staphylococcus aureus e Staphylococcus xylosis houve formação de halos de inibição de $15 \mathrm{~mm}$ e $12 \mathrm{~mm}$ respectivamente. Nas placas semeadas com Pseudomonas aeruginosa não houve formação de halos de inibição (Figura 1). Nas placas controle houve crescimento bacteriano em toda sua extensão.

\section{Experimento 3:}

Houve inibição do crescimento de Staphylococcus nos $5 \mathrm{~mm}$ 


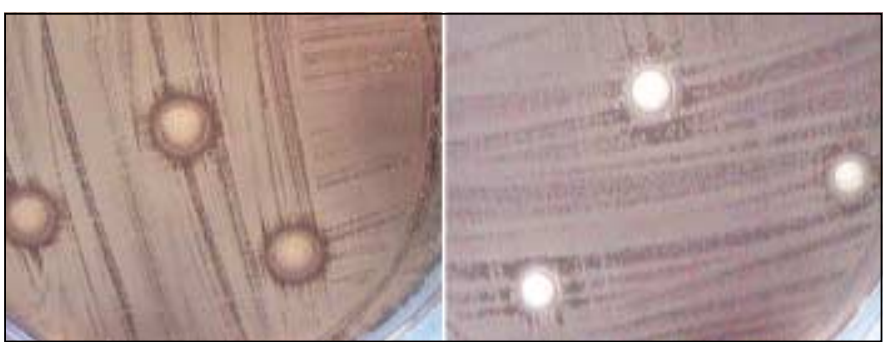

Figura 1 - Placas de ágar sangue semeadas com $S$. aureus (foto da esquerda) e Pseudomonas sp (foto da direita). Note o halo em torno das gotas de cianoacrilato formado na placa com $S$. aureus e a sua ausência na placa com Pseudomonas sp

iniciais do trajeto das micro-perfurações nos tubos contendo cianoacrilato. Aqueles semeados com Pseudomonas aeruginosa e os tubos controle apresentaram crescimento bacteriano em todo o trajeto das micro-perfurações.

\section{DISCUSSÃO}

Os estudos avaliam possível efeito inibitório do adesivo cianoacrilato sobre o crescimento de algumas bactérias ${ }^{(4)}$, utilizando isobutil cianoacrilato e em outro trabalho ${ }^{(6)}$, utilizando alquil 2-cianoacrilato, demonstraram efeito inibitório "in vitro" contra microrganismos gram positivos.

As amostras de cianoacrilato Super Bonder ${ }^{\circledR}$ testadas não apresentaram crescimento microbiano nos meios de culturas padronizados. Faz-se necessária a avaliação da esterilidade do produto com a utilização de meios de cultura especiais para outros patógenos como anaeróbios, acanthamoebas e mycobactérias.

A avaliação da atividade biocida do adesivo foi feita com a utilização de diferentes aplicações do adesivo sobre o inóculo, para que pudesse ser avaliada a importância do fenômeno de polimerização, que ocorre quando o adesivo entra em contato com outros meios, na possível atividade biocida do adesivo.

Os testes aqui apresentados para demonstração de um possível efeito bacteriostático ou bactericida, demonstraram a ausência de qualquer efeito inibitório sobre o crescimento da cepa de Pseudomonas aeruginosa utilizada, independentemente da forma de contato do adesivo com o inóculo e meio de cultura. Entretanto, em relação às cepas de Staphylococcus aureus e Staphylococcus xylosis, observou-se que houve efeito inibitório sobre seu crescimento durante o contato do inóculo com o adesivo. $\mathrm{O}$ crescimento do microrganismo foi observado nas culturas das películas de adesivo retiradas e, nas placas de ágar sangue, após a retirada do adesivo dos micro-orifícios (Experimento 1), sugerindo que as bactérias estavam em estado latente, aderidas à película formada pelo adesivo. Os resultados obtidos nos experimentos 2 e 3 também sugerem que a atividade bacteriostática do adesivo sobre as cepas testadas de Staphylococcus aureus e Staphylococcus xylosis parece ser diretamente proporcional à superfície de contato com o inóculo, ou seja, ocorre uma inibição nas áreas superficiais, que entram em contato direto com o adesivo, com o crescimento bacteriano nas áreas mais profundas das micro-perfurações.

As amostras de cianoacrilato Super Bonder ${ }^{\circledR}$ testadas não apresentaram crescimento de patógenos em meios de ágar sangue, chocolate e Sabouraud, o que viabiliza, do ponto de vista microbiológico, a utilização do produto para o tratamento de afinamentos e microperfurações corneais. Entretanto, sua atividade biocida "in vitro" é ausente frente a importantes agentes causadores de infecção corneal, como o Staphylococcus aureus e Pseudomonas aeruginosa ${ }^{(9)}$, recomendadose a manutenção do tratamento com antibioticoterapia apropriada, quando da utilização do adesivo cianoacrilato Super Bonder ${ }^{\circledR}$, em vigência de quadros infecciosos.

Embora os efeitos tóxicos, ela possibilita maior acessibilidade em determinadas regiões do Brasil.

\section{ABSTRACT}

Purpose: To evaluate the sterility of the Super Bonder ${ }^{\circledR}$ cyanoacrylate and its biocide activity on microorganisms. Methods: For verification of contamination, twenty samples of Super Bonder ${ }^{\circledR}$ cyanoacrylate were applied to brain heart infusion (BHI) media and incubated at $37^{\circ} \mathrm{C}$. After 7 days of incubation, they were plated on blood, chocolate and Sabouraud agar. For the determination of the biocide effect, Staphylococcus xylosis, Staphylococcus aureus and Pseudomonas aeruginosa strains of the American Type Culture Collection (ATCC) were used in three different models, modifying the way Super Bonder ${ }^{\circledast}$ cyanoacrylate application (in microholes, pipes and on the agar). Results: No positive growth was observed on the plated samples of cyanoacrylate in brain heart infusion. In the plates with microholes, growth of $P$. aeruginosa and inhibition of S. xylosis and S. aureus were observed. After removal of the adhesive, bacterial growth in all microholes was observed. In the plates with S. xylosis and $S$. aureus the presence of an apparent inhibition halo, that did not occur with $P$. aeruginosa was observed. Conclusion: The performed tests of sterility demonstrated that Super Bonder ${ }^{\circledast}$ cyanoacrylate is a safe alternative, regarding sterility, for treatment of small corneal perforations. No bacteriostatic or bactericidal effects were demonstrated with the tested cyanoacrylate, regarding $S$. aureus, S. xylosis and P. aeruginosa.

Keywords: Cyanoacrylates/therapeutic use; Tissue adhesives; Cornea/injuries; Anti-infective; Pseudomonas aeruginosa/isolation \& purification; Staphylococcus/isolation \& purification

\section{REFERÊNCIAS}

1. Bonatti JA, Steffano JT, Matheus LCA, Oliveira GA, Suzuki H, Kara-José N. Desenvolvimento de adesivo tecidual fibrínico para uso experimental em perfurações corneanas. Arq Bras Oftalmol 1995;58:354-6. 
2. Freitas D. Laceração de córnea e esclera. In: Moreira Jr. CA, Freitas D, Kikuta HS. Trauma ocular. Rio de Janeiro: Cultura Médica; 1997. p.25-30.

3. Langston RH. Técnicas em transplante de córnea. In: Jaffe NS. Atlas de cirurgia ocular. São Paulo: Manole; 1993. p.2-14.

4. Bhaskar SN, Frisch J, Margetis PM, Leonard F. Application of a new adhesive in periodontic and oral surgery. Oral Surg Oral Med Oral Pathol 1966;22:526-35

5. Sato ES, Belfort Jr R. Tratamento cirúrgico das perfurações corneanas não infectadas. In: Belfort Jr R, Kara-Jose N. Córnea clínica e cirúrgica. São Paulo: Roca; 1996. p.483.
6. Garrido C, Teles D, Koji W, Freitas D. Cola terapêutica de cianoacrilato nas perfurações corneanas. Arq Bras Oftalmol 1999;62:683-6.

7. Jandinski J, Sonis S. In vitro effects of isobutyl cyanoacrylate on four types of bacteria. J Dent Res 1971;50:1557-8.

8. Lehman RA, West RL, Leonard F. Toxicity of alkyl 2-cyanoacrylate. II. Bacteria growth. Arch Surg 1966;93:447-50.

9. Murray RP, Rosenthal KS, Kobayashi, GS, Pfaller MA. Pseudomonas e microrganismos relacionados. In: Murray RP, Rosenthal KS, Kobayashi GS, Pfaller MA Microbiologia médica. Rio de Janeiro: Guanabara-Koogan; 2000. p.215-7.

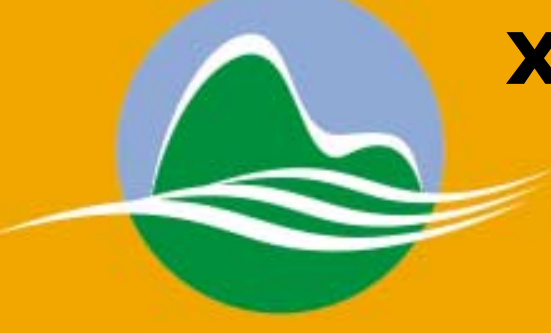

\section{Congresso Brasileiro de Prevenção da Cegueira e Reabilitação Visual}

4 a 7 de setembro de 2004 Rio Centro - Pavilhão 5 - Rio de Janeiro

\section{SORTEIO DE UM CARRO ZERO KM DURANTE O EVENTO}

FAÇA SUA INSCRIÇÃO ANTECIPADA E TENHA MAIS CHANCES DE GANHAR UM LINDO PEUGEOT 206 ZERO KM

Para concorrer, é necessário estar inscrito no Congresso

Congressistas inscritos até $30 / 05 / 2004$ 3 CHANCES ( 3 NÚMEROS)

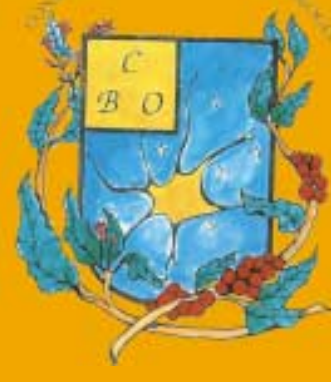

Congressistas inscritos até $30 / 07 / 2004$ 2 CHANCES (2 NÚMEROS)

Congressitas inscritos após $30 / 07 / 2004$ 1 CHANCE (1 NÚMERO)

Consulte regulamento no site: www.cboprevcegueira04.com.br 